\title{
Operator Dies after Excavator Tips Over the Side of a Bridge into River
}

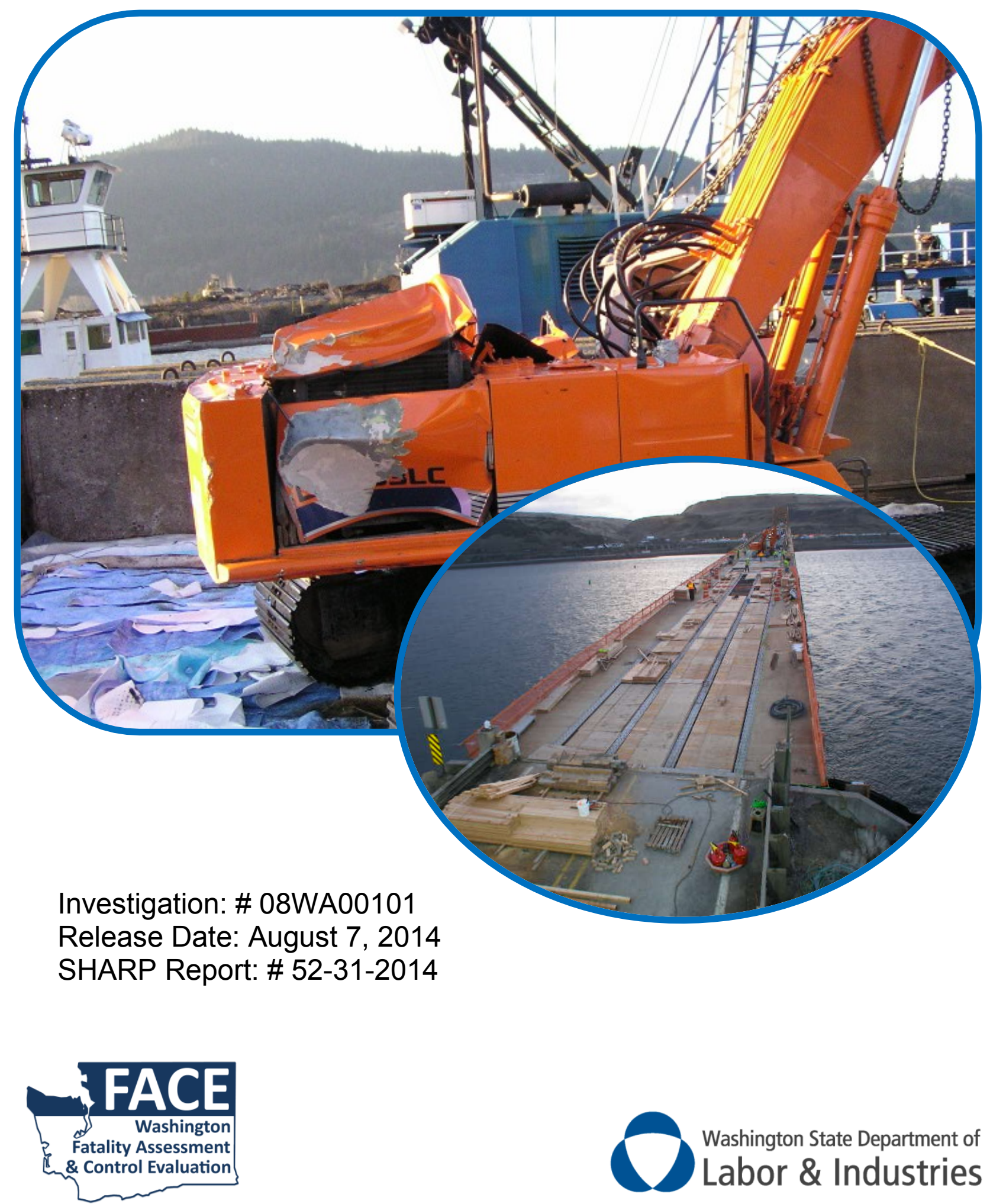




\section{TABLE OF CONTENTS}

CONTENTS

PAGE

DEFINITIONS

3

SUMMARY

4

RECOMMENDATIONS

4

INTRODUCTION

5

Employer

5

Employer Safety/Training Program

Operator

MACHINE

Excavator

Load Charts

Excavator Attachment (Slab Crab)

Deck Slabs

Removing Deck Slabs

INVESTIGATION

Project and Incident Scene

Incident

CONTRIBUTING FACTORS

CAUSE OF DEATH

RECOMMENDATIONS AND DISCUSSION

ACKNOWLEGEMENTS

APPENDIX A: JOB HAZARD ANALYSIS FORM AND EXAMPLE 27

REFERENCES

28

INVESTIGATOR INFORMATION

FACE PRORGRAM INFORMATION 


\section{DEFINITIONS}

$\begin{array}{ll}\text { ANSI } & \text { American National Standards Institute } \\ \text { APP } & \text { Accident Prevention Program } \\ \text { DOSH } & \text { Division of Occupational Safety and Health } \\ \text { FACE } & \text { Fatality Assessment and Control Evaluation } \\ \text { GPS } & \text { Global Positioning System } \\ \text { HSE } & \text { Health and Safety Executive } \\ \text { IUOE } & \text { International Union of Operating Engineers } \\ \text { JHA } & \text { Job Hazard Analysis } \\ \text { LOLER } & \text { Lifting Operations and Lifting Equipment Regulations } \\ \text { PCSA } & \text { Power Crane and Shovel Association } \\ \text { NIOSH } & \text { National Institute for Occupational Safety and Health } \\ \text { SHARP } & \text { Safety and Health Assessment and Research for Prevention } \\ \text { WA } & \text { Washington State } \\ \text { WSDOT } & \text { Washington State Department of Transportation }\end{array}$




\section{SUMMARY}

On January 15, 2008 a 62-year-old equipment operator was fatally injured when the hydraulic excavator he was operating tipped over the side of a bridge, falling 60 feet into the river below. The operator was working on the demolition of the bridge by removing cut concrete slabs from the bridge deck. He was using the hydraulic excavator which was equipped with a type of bucket attachment (Slab Crab) designed for bridge deck and concrete slab removal work. He was removing the concrete slabs in order to position them for removal. On the fatal lift, the concrete slab was freely suspended from the Slab Crab with a two leg bridle chain sling. In order to clear the guardrail, the operator extended the arm of the excavator to raise the load. This caused the load to exceed the excavator's load limit radius. The excavator became unbalanced and tipped towards the edge of the bridge deck. The operator attempted to correct the imbalance by arming-in, or decreasing the distance of the load from the excavator. However, arming in the load caused the excavator to slide towards the edge of the bridge. The operator was trying to get out of the cab when the excavator tipped over the edge of the bridge. Workers immediately activated the emergency response protocols. The operator was retrieved from the river in less than 10 minutes and CPR was performed in the rescue boat. EMS arrived at the scene within 15 minutes. The operator was pronounced dead at the hospital approximately $1 \frac{1}{2}$ hours after the excavator tipped over the bridge.

To prevent similar incidents, Washington State Fatality Assessment and Control Evaluation (FACE) recommends that:

Employers:

- Plan excavator picks to ensure that the stability of the machine can be maintained by the operator while lifting freely suspended loads.

- Ensure that operators participate in project and task pre-planning Job Hazard Analysis (JHA) activities.

- Consider installing an audible and/or visual load safety warning device or a safe load indicator to alert the equipment operator before the object handling capacity or load moment is reached.

Operators:

- Perform a JHA on any changes in the intended work plan prior to changing the operational work plan.

- Communicate with riggers to address any lift that does not follow the intended lifting plan. 


\section{INTRODUCTION}

On January 15,2008 , The Washington State Division of Occupational Safety and Health (DOSH) notified the Washington State Fatality Assessment and Control Evaluation (FACE) Team of the death of a 62-year-old equipment operator.

After reviewing the DOSH investigation report, WA FACE investigators interviewed the employer's safety manager. During the meeting, the safety manager provided information regarding employer history, organization, and health and safety programs, as well as details related to the incident. In the course of the FACE investigation, documents reviewed included:

- Police report.

- DOSH investigation.
- Employer's investigation.

- Coroner's report.

\section{Employer}

The employer is a construction company that primarily builds and restores bridges. They are also involved in other construction work, including erecting concrete and steel structures. They have been in business since 1964, operate in six western states, and employ approximately 200 fulltime employees. The employer also hires temporary equipment operators from the International Union of Operating Engineers (IUOE) for specific projects.

\section{Employer Safety Training Program}

The employer has a comprehensive written safety management program. When hired, new employees attend an orientation which incorporates the employer's program. The orientation covers:

- Safety roles and responsibilities for employees and management.

- Expectations in regard to tools, machinery, and vehicles.

- Reporting procedures for employees.

- Potential disciplinary action if an employee violates employer safety policies.

The employer's comprehensive safety training program is overseen by the safety director who dedicates $100 \%$ of his time to safety issues. The safety director manages two primary safety officers that assist him in administering the safety program. Both safety officers were assigned to this project. The employer has a safety committee that meets quarterly, as well as smaller safety committees for cranes, marine jobs, and fall prevention that meet on a monthly basis. Crews working on a project have weekly 
safety meetings on the jobsite. In addition, crews meet for five minutes at the beginning of each shift and after lunch to review plans for the day and remind workers of safety concerns. The employer also creates project and task-specific safety plans by completing a JHA.

\section{Operator}

The operator was a journeyman heavy equipment operator who had worked for the employer for approximately one month at the time of the incident. The operator was hired from the local IUOE for this project because of his experience with the particular excavator the employer planned to use.

After being hired, the operator participated in the company orientation which involved training in 25 topic areas including hydraulic lifting equipment, rigging, hazard communication, and the JHA process. The operator was also required to demonstrate his ability to operate the excavator he would be using. He was also a certified crane operator and had recently worked a job operating a 60-ton crane.

Prior to the incident, the operator had successfully picked 34 concrete slabs from the deck, including one that morning. The Washington State Department of Transportation (WSDOT) inspector estimated that $25 \%$ of the completed picks were of similar size and weight as the concrete slab involved in the fatal lift.

\section{MACHINE}

\section{Excavator}

The excavator was a Hitachi model UH083LC hydraulic crawler (also known as a trackhoe). The features of this excavator include:

- An 18 foot 5 inch boom with a 9 foot 6 inch arm.

- Minimum swing radius of 3.65 meters (12 feet).

- Maximum traction force of 137 kilonewtons (30,900 pounds of force).

- Load rating over front (cab and boom parallel with track) with arm at maximum reach on level ground of 5,190 pounds.

- Load rating over side (cab and boom perpendicular to track) with arm at maximum reach on level ground of 3,210 pounds. 


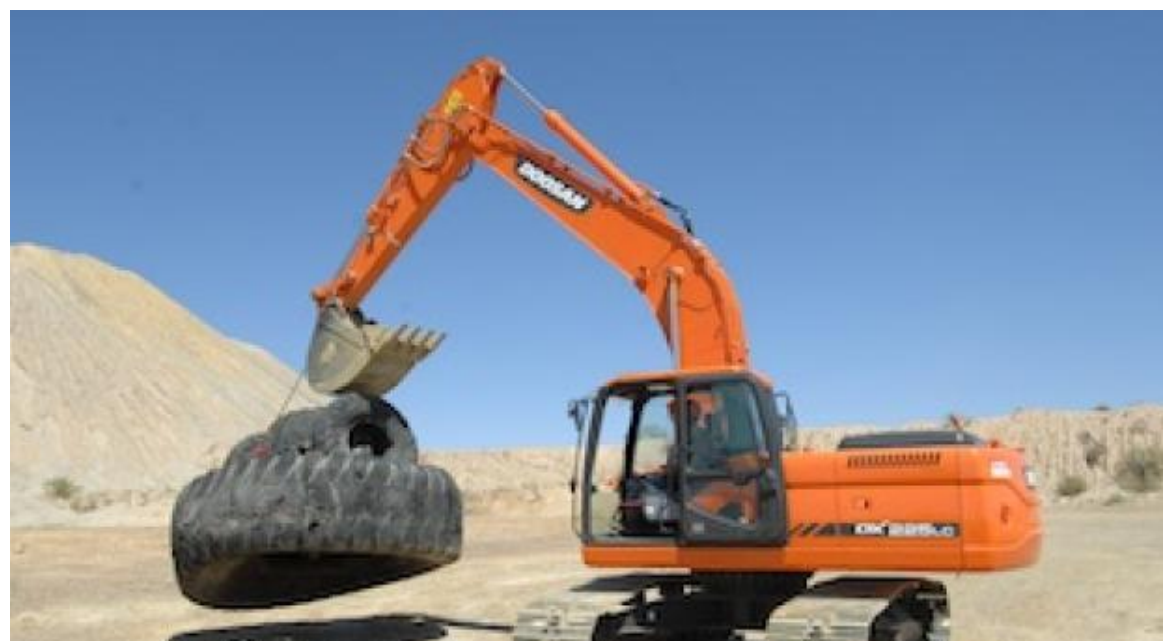

Photo 1: An excavator completing an over the side load test. Notice the cab and counterweight are perpendicular to the tracks

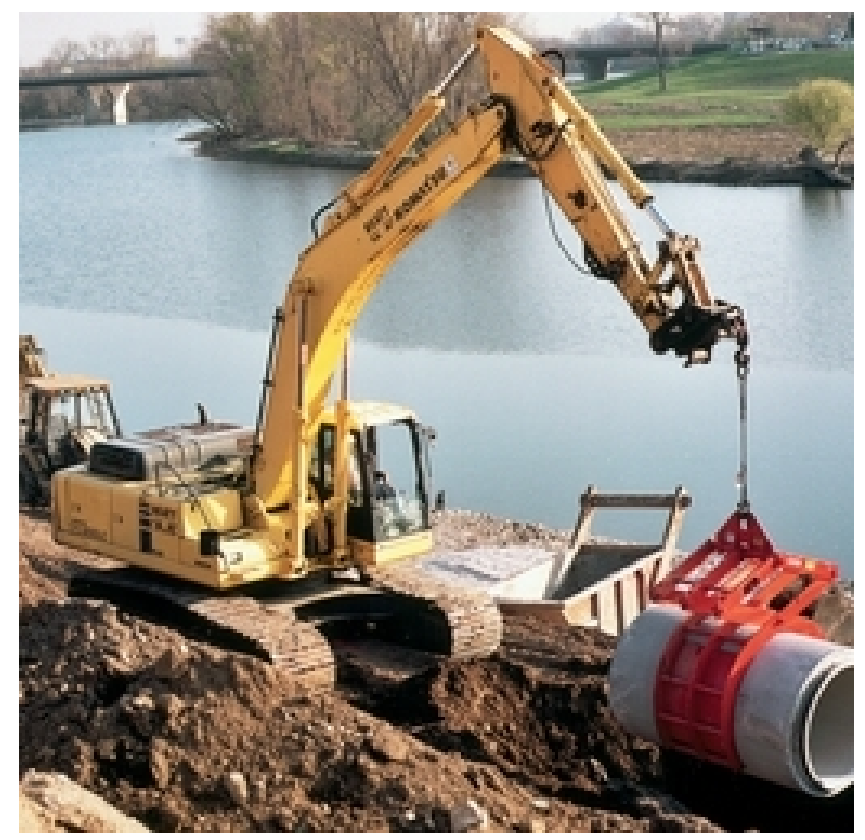

Photo 2: Photo of an excavator completing an over the front lift. Notice the cab and counterweight are in line with the tracks

The excavator was purchased used with an accompanying safety manual. According to the safety manager, the excavator was the best piece of machinery to use for this project due to the limited space on the bridge to move the slabs, and was in good condition prior to the incident. 


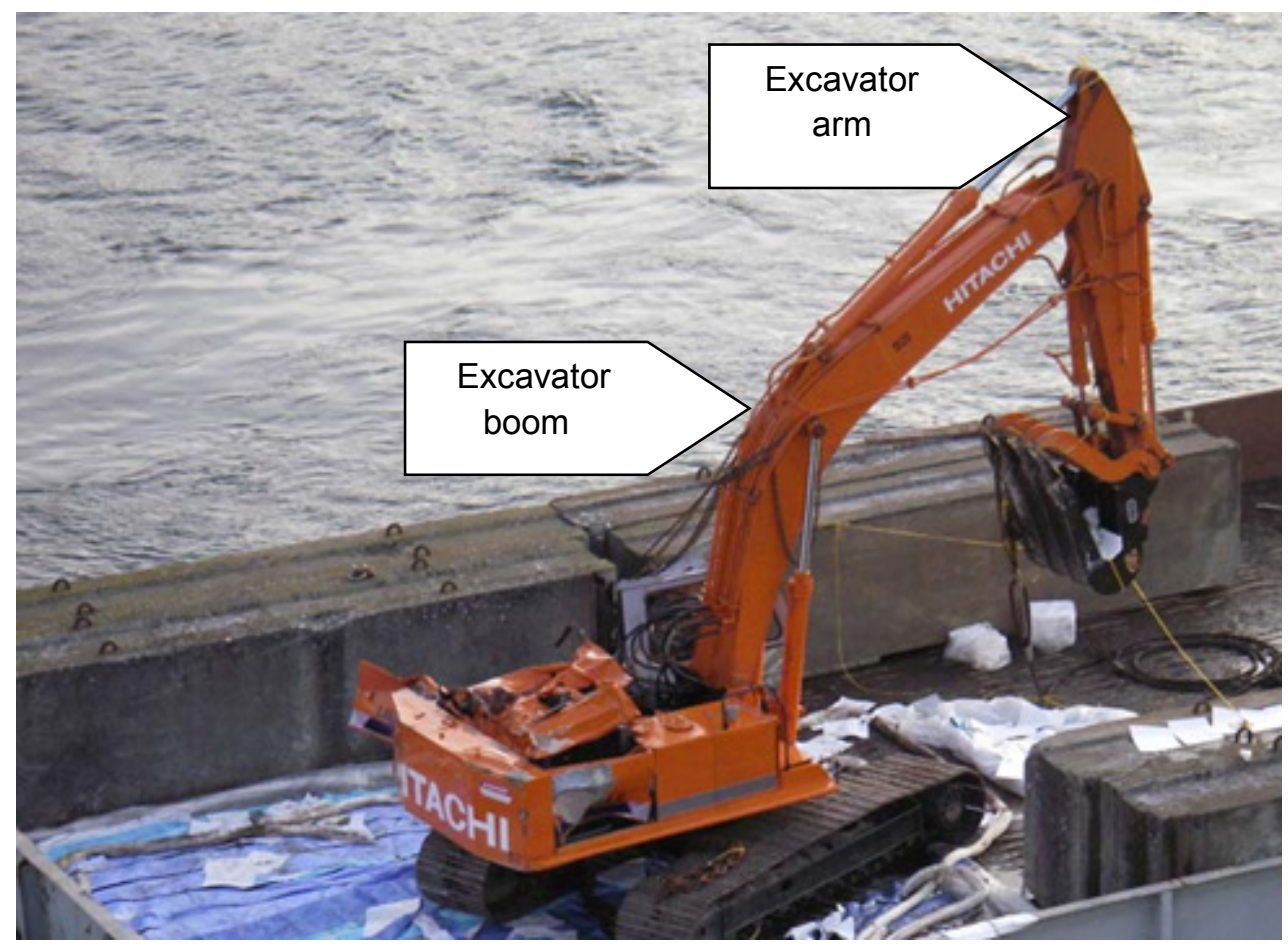

Photo 3: Hitachi Excavator UH083LC on recovery barge after incident

\section{Load Charts}

The employer was unable to acquire the load charts specific to the UH083LC excavator from the seller or manufacturer. Instead, the employer estimated the excavator's load capacity using load charts for a Hitachi EX200LC excavator, which the employer believed was most similar to the UH083LC. Load charts are designed with a safety factor of $25 \%$, meaning the actual load weight required to tip the machine is $25 \%$ greater than what is listed on the load chart. No load chart was posted in the excavator for the operator to consult.

The load chart data for the Hitachi EX200LC and the Hitachi UH083LC are shown in Table 1. The table shows that the capacity of the Hitachi UH083LC was between $9.5 \%$ to $17.3 \%$ less than the EX200LC at the same load height and over the side of the machine. For example, the data for the EX200LC show that at a load point height of 15 feet, the load radius to the side would be 20 feet for an 8,460 pound load. The suspended load capacity for the Hitachi UH083LC at the same load point height and side radius would be 7,660 pounds, or $9.5 \%$ lower. With a load point height of 10 feet, the radius to the side would be 25 feet for a 5,970 pound load for the EX200LC, and $17.3 \%$ (1030 pounds) lower using the UH083LC. The actual tipping point for a load height of 10 feet without the $25 \%$ safety factor applied would be 10,488 pounds at a load radius of 20 feet and 7,463 pounds at a load radius of 25 feet for the EX200LC. 
Table 1: Comparison of EX200LC and UH083LC Load Charts

\begin{tabular}{ccccc}
\hline $\begin{array}{c}\text { Suspended load } \\
\text { weight } \\
\text { (pounds)EX200LC }\end{array}$ & $\begin{array}{c}\text { Suspended Load } \\
\text { weight (pounds) } \\
\text { for UH083LC }\end{array}$ & $\begin{array}{c}\text { Load } \\
\text { height } \\
\text { (ft) }\end{array}$ & $\begin{array}{c}\text { Load Distance } \\
\text { over the Side } \\
\text { (ft) }\end{array}$ & $\begin{array}{c}\text { Percent } \\
\text { Decrease from } \\
\text { EX200LC }\end{array}$ \\
\hline $8,460^{\mathrm{a}}$ & $7,660^{\mathrm{a}}$ & 15 & 20 & $9.5 \%$ \\
$6,170^{\mathrm{a}}$ & $5,150^{\mathrm{a}}$ & 15 & 25 & $16.5 \%$ \\
$8,390^{\mathrm{a}}$ & $7,380^{\mathrm{a}}$ & 10 & 20 & $12.1 \%$ \\
$5,970^{\mathrm{a}}$ & $4,940^{\mathrm{a}}$ & 10 & 25 & $17.3 \%$ \\
$10,488^{\mathrm{b}}$ & $9,225^{\mathrm{b}}$ & 10 & 20 & $12.0 \%$ \\
$7,463^{\mathrm{b}}$ & $6,175^{\mathrm{b}}$ & 10 & 25 & $17.3 \%$ \\
\hline
\end{tabular}

${ }^{a}$ With $25 \%$ safety factor applied

${ }^{\mathrm{b}}$ Without $25 \%$ safety factor applied

\section{Excavator Attachment (Slab Crab)}

The excavator was fitted with an attachment called a Slab Crab. The Slab Crab is a 42 inch bucket manufactured by Kenco (model EX250) weighing 3,000 pounds and capable of moving slabs of concrete up to 12 inches thick. According to Kenco's website (http://kenco.com/products/slab-crab), Slab Crabs are specifically designed for concrete slab removal projects and are available for various sizes and types of machinery. Models are available for $20,000-150,000$ pound excavators, as well as backhoes and skid steer machines.

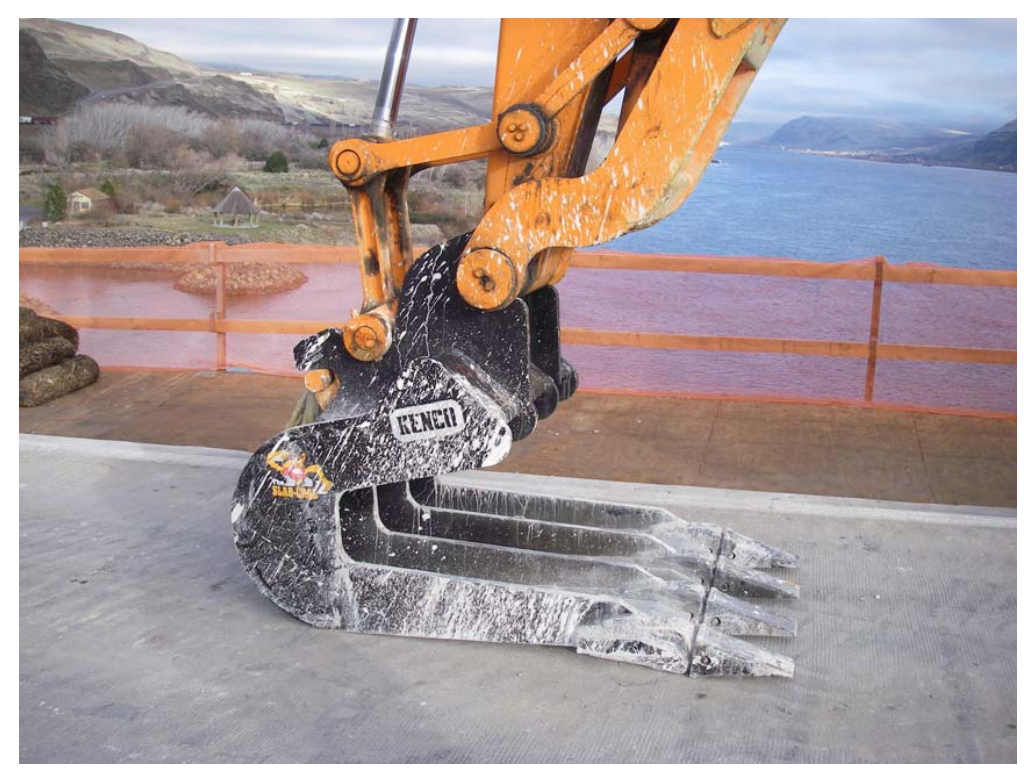

Photo 4: Slab Crab bucket attachement 


\section{Deck Slabs}

According to the project engineer, concrete slab weights were estimated using as-built bridge plans and a density of 125 pounds per cubic foot based upon 120 pounds per cubic foot for concrete plus an additional five pounds per cubic foot for the overlay.

The initial bridge deck demolition plan stated that the concrete slabs were to be cut with a corner to corner length of 10 feet. The plan included inconsistent estimated weights for the concrete slabs being removed. For example, one estimate described the concrete slabs as 11 feet 7 inches long and 6 feet 8 inches wide and weighing 4,200 pounds. Using these dimensions and an average thickness of 8 inches, similar to the incident slab, the calculated weight at 125 pounds per cubic foot would be 6,435 pounds, not 4,200 pounds. A separate estimate in the same plan described the concrete slabs weighing 4,800 pounds. The revised demolition plan, after the incident, stated that the concrete slabs were to be cut 8 feet corner to corner and weigh 4,506 pounds for smaller slabs and 6,186 pounds for larger slabs.

Table 2: Estimated and Actual Concrete Slab Dimensions and Weight

\begin{tabular}{lll}
\hline $\begin{array}{l}\text { Demo Plan } \\
\text { Slab }\end{array}$ & $\begin{array}{l}\text { Estimated Dimensions } \\
\text { Length X Width X Thickness }\end{array}$ & Estimated Weight \\
\hline $11 / 21 / 2007$ & $139 \times 80 \times 7$ & 4,200 pounds \\
$11 / 21 / 2007$ & $139 \times 80 \times 7$ & 4,800 pounds \\
$12 / 27 / 2007$ & $96 \times 90 \times 7$ & 4,200 pounds \\
$2 / 4 / 2008$ & $96 \times 78 \times 7$ (standard panels) & 4,506 pounds \\
$2 / 4 / 2008$ & $96 \times 102 \times 7$ (larger panels) & 6,186 pounds \\
\hline Actual Slab & Dimensions & Actual Weight \\
\hline & $120 \times 86 \times 8$ & 6,600 pounds \\
\hline
\end{tabular}

The concrete slab involved in the incident measured 120 inches long by 86 inches wide and an average of 8 inches thick, and weighed 6,600 pounds. This equates to a density of 138 pounds per cubic foot. The corner to corner length was 13 feet 3 inches. The combined weight of the concrete slab and the Slab Crab bucket attachment was approximately 9,600 pounds, more than 3,000 pounds over the tipping point at 10 feet height while extended 25 feet over the side. According to estimates from the initial DOSH inspection, the concrete slab involved in the incident was approximately 2,000 pounds heavier than estimated. 


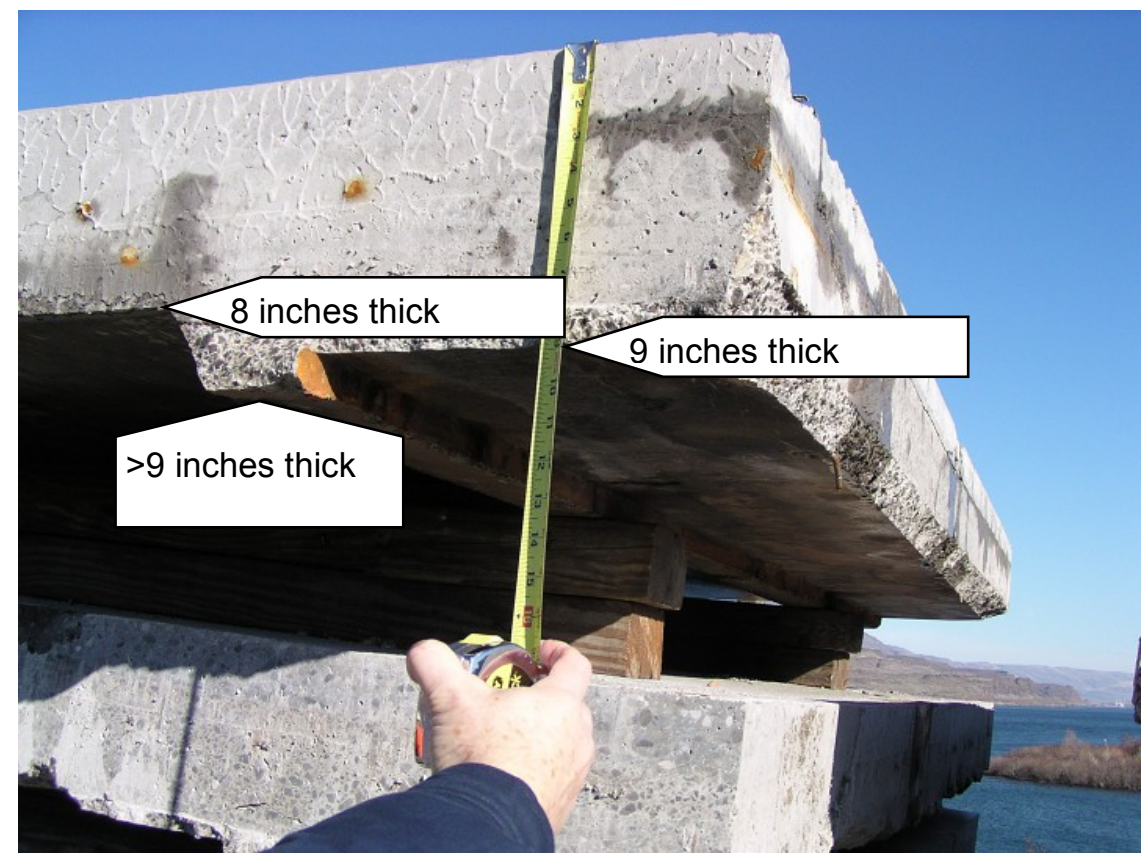

Photo 5: Concrete slab involved in incident showing that thickness exceeded 8 inches

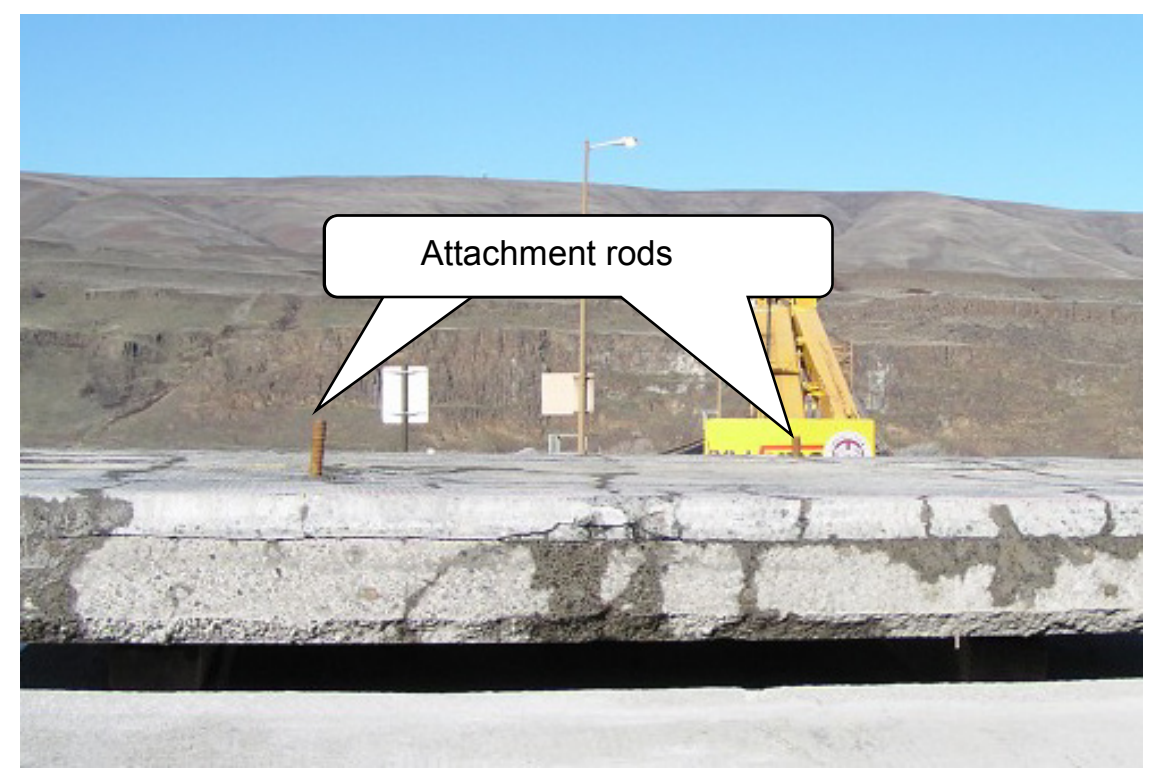

Photo 6: Concrete slab with arrows pointing at threaded rods used for hoisting by chain sling

\section{Removing Deck Slabs}

The employer used two methods for removing the bridge deck. The primary method was to first cut the concrete slabs into rectangular shapes with a corner to corner length 
of 10 feet. Then, the excavator operator would use the excavator's Slab Crab bucket attachment to break the concrete slab free. The operator would then lift the slab in the horizontal position with the Slab Crab without using the chain sling, rotate the excavator 180 degrees, and place the slab flat on cribbing laid out on the deck behind the excavator. A forklift would then haul the slab away.

The second method for removing the bridge deck was used when bridge structural members, transverse diaphragms, prevented direct use of the Slab Crab. Transverse diaphragms are used, depending on their location, to resist lateral wind loads or transfer the loads from the deck down to the bearings ${ }^{[1]}$ For this method, holes were drilled in opposite corners of the cut concrete slabs. Threaded rods, plates, nuts and swivel pad eyes were inserted into the corner holes and utilized as rigging connection points. A two-leg bridal chain sling attached the rigging connection points to the Slab Crab. The excavator would then raise the Slab Crab to apply tension on the chain rigging and break through the remaining uncut concrete. Each leg of the bridal chain consisted of a grade 100 chain that was 20.5 inches long; the working load limit was 12,300 pounds in a two leg 60 degree configuration.

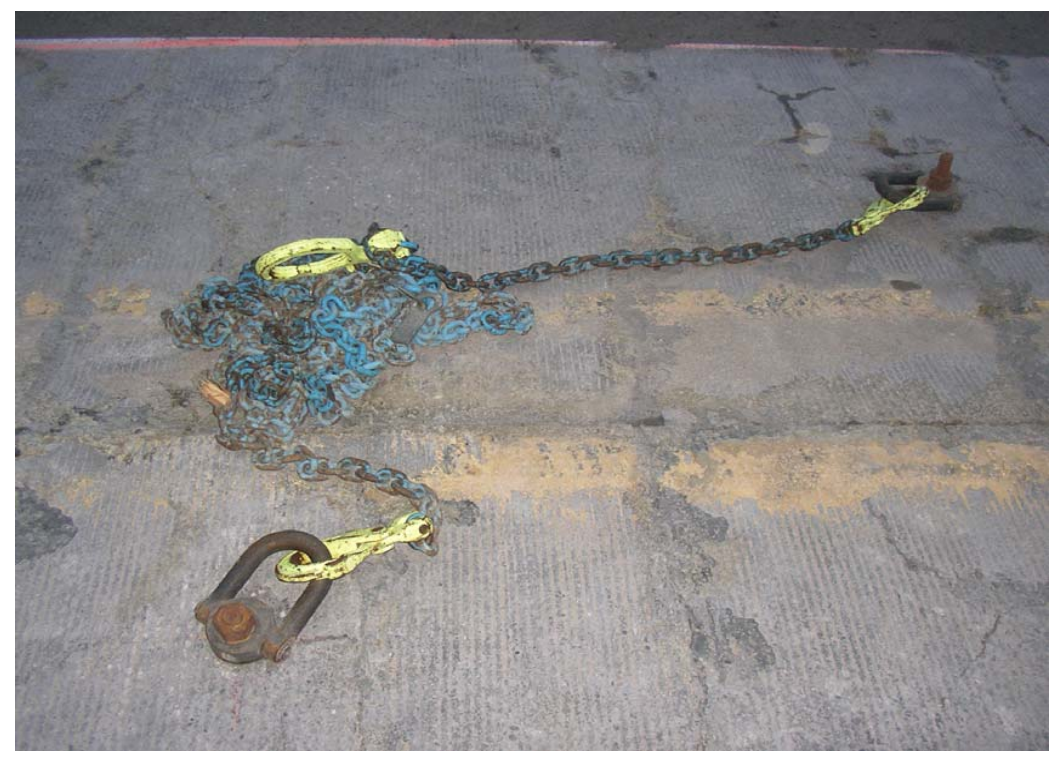

Photo 7: Chain rigging format and chain sling used to lift concrete slabs with transverse diaphragms

Both methods of bridge deck removal required that the slabs be raised, moved, and lowered back into the horizontal position parallel to the deck. The operator was instructed to keep the load as close to the excavator as possible and to stay within the temporary guardrails, approximately 19.5 feet from the center of the bridge, when rotating the excavator the 180 degrees to the drop point for the concrete slabs. 


\section{INVESTIGATION}

\section{Project and Incident Scene}

The employer was hired as the general contractor by WSDOT to demolish and replace a deteriorating concrete bridge deck. The 2,567 foot long highway bridge spans a large river. Project work started in November 2008, approximately 45 days prior to the incident. The initial phase of the project involved the construction of falsework, a safety deck below the existing deck, and temporary walkways with temporary guardrails on either side of the bridge. Demolition of the bridge decking began about two weeks before the incident.

According to the employer, the operator was present at the time of the load testing of the excavator with a section of a concrete Jersey barrier weighing 6,140 pounds. The load test consisted of an operator moving the Jersey barrier 25 feet over the front of the excavator from center as well as 20 feet to the side with the Slab Crab attachment. The excavator was stable in both instances. The project engineer and project superintendent told the operator that while performing picks it was important to keep the load as close as possible to the excavator to maintain its stability. On the day before the incident, two project safety officers observed the operator doing picks and saw no safety concerns with how he operated the excavator.
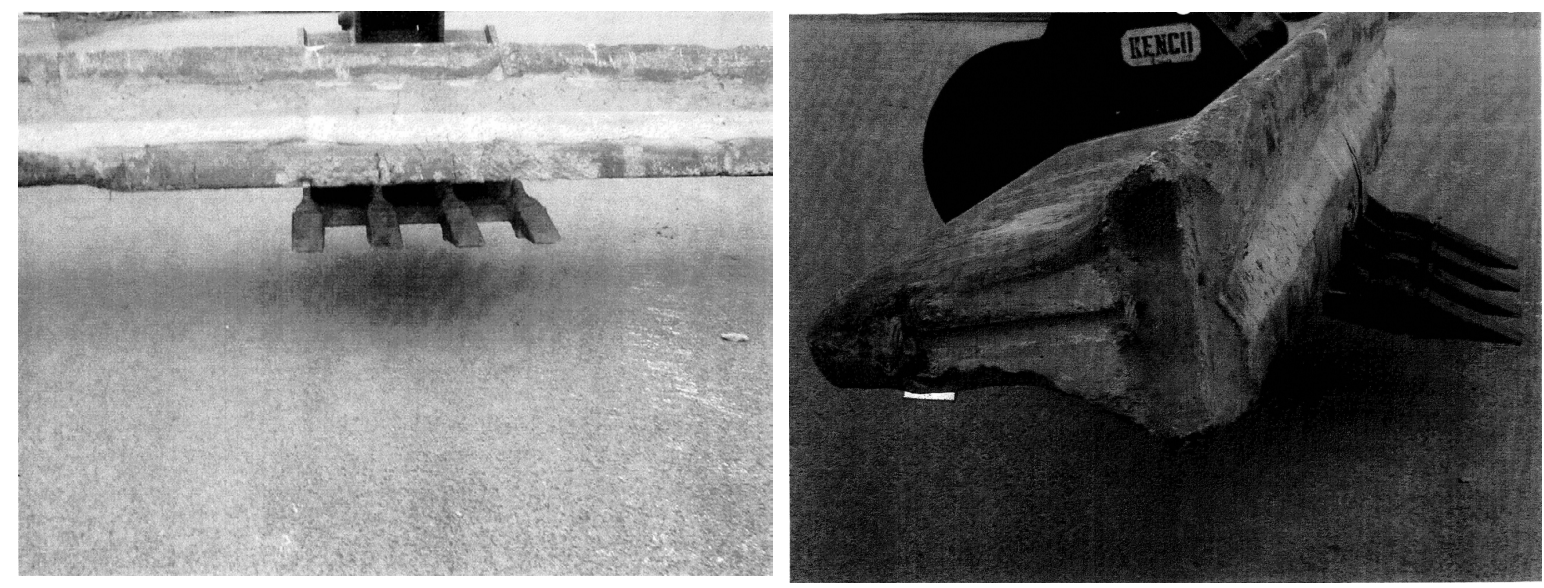

Photos 8\&9: Front and side view of Slab Crab during load testing with a concrete Jersey barrier

On the day of the incident, there were approximately 12 employees and one WSDOT inspector onsite. There were six employees working in the vicinity of the operator. Two were working directly with the operator. The two working directly with the operator were connecting and disconnecting the rigging to and from the Slab Crab. 
At the time of the incident, workers were cutting the existing concrete bridge deck into slabs and removing them (see page 10 for a description of this process). Two work crews, a day crew and a night crew, consisting of machine operators, carpenters, and laborers, had removed 68 slabs prior to the incident, with the operator removing approximately half of these slabs.

The weather on the day of the incident was clear and dry with the wind blowing from the west at approximately 26 miles per hour.

\section{Incident}

On January 15,2008 , the operator started his shift at approximately 8 am by participating in the safety huddle held prior to starting work. The operator then started removing concrete slabs that were cut on the previous day. The first slab was removed using a chain rigged to the slab crab because it contained a transverse diaphragm.

On the first lift, the operator saw that the concrete slab tilted about 45 degrees instead of being flat as was intended. The tilt added excess tension to the chain. After rotating the excavator 180 degrees and setting the slab at the drop point, the operator began his second pick.

The second slab, like the first slab, contained a transverse diaphragm and needed to be rigged to the Slab Crab by the chain and sling. To prevent this concrete slab from tilting like the previous slab, the operator asked the riggers to add about 12 to 18 inches of length in the chain. When lifted, this caused the second concrete slab to be positioned more vertically than the previous slab with one corner hanging down.

According to one of the laborers onsite, the operator initially swung the load to the left, until he saw a carpenter working in the area. He then changed direction, and swung the load to the right. The laborer also stated that it appeared that he swung the load too fast.

According to the safety manager, in order to raise a load using this excavator, the operator can either boom up, or arm-out. To boom-up means bringing the boom closer to the excavator body, thus raising the load. To arm-out means to extend the arm away from the excavator body. This moves the load further away from the body of the excavator while raising the load. 
The project engineer observed that as the operator rotated the excavator, it appeared the suspended slab would contact the guardrail. In order to raise the slab and clear the guardrail, the operator armed-out, or extended the arm.. This suspended the slab beyond the designated safety zone, the temporary wooden walking deck and guardrail, established by the employer. The project engineer estimated that the arm and boom were at or near full extension, approximately 25 feet. The slab successfully passed over the guardrail, but with the arm near full extension to the side, the excavator became unstable and began to tip.

The operator attempted to correct this and stabilize the excavator by pulling the arm in, a normal corrective measure on solid ground for this type of machine. However, in this case, the load had passed below the edge of the bridge. This caused the excavator to slide sideways toward the edge of the bridge deck.

Witnesses stated that the excavator initially slid sideways on its tracks towards the side of the bridge. Witnesses also observed that the excavator moved relatively slowly at first, but once it was past the tipping point, it quickly went over the side of the bridge. The operator was attempting to get out of the cab as the excavator went over the side of the bridge, falling 60 feet into water that was 20 feet deep (photo 10). The WSDOT inspector was approximately 15 feet away when the excavator tipped over the bridge.

The project team initiated emergency protocols immediately, contacting 911 and deploying a rescue boat. The rescue boat got to the operator in less than 10 minutes and team members began CPR. EMS arrived on the scene in 15 minutes and transported the operator to the hospital, where he was declared dead approximately $11 / 2$ hours after the incident 


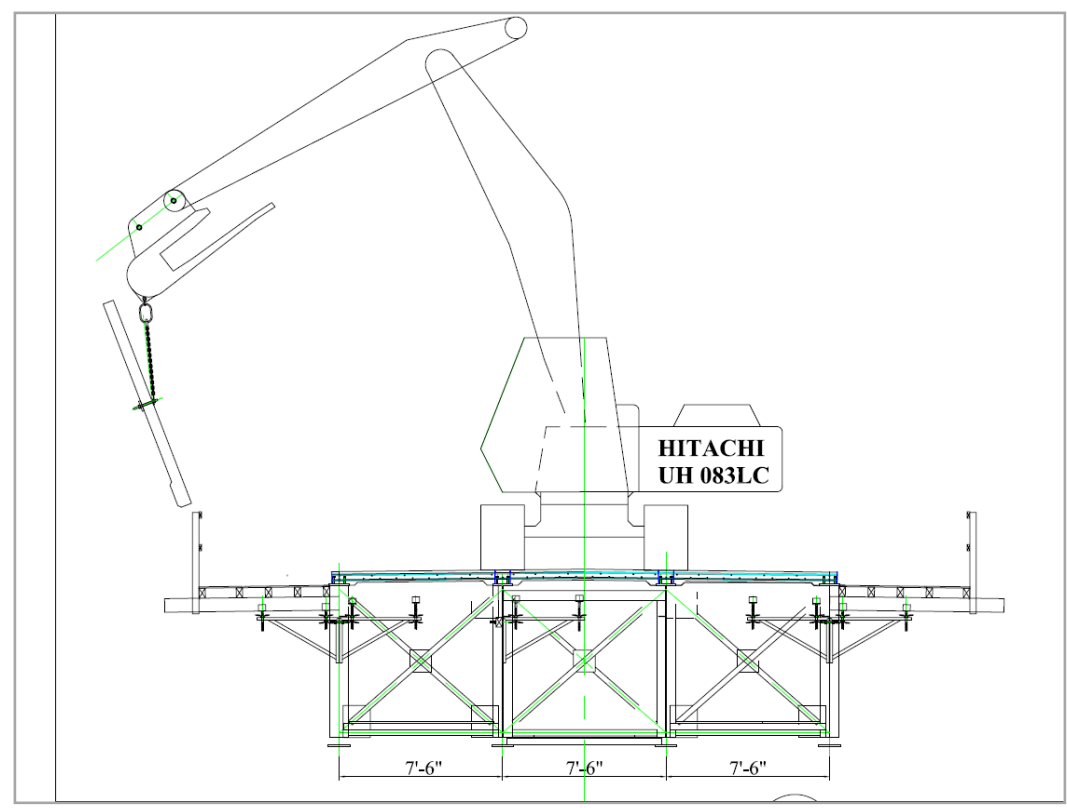

Diagram 1: The position of concrete slab before excavator started to become unstable

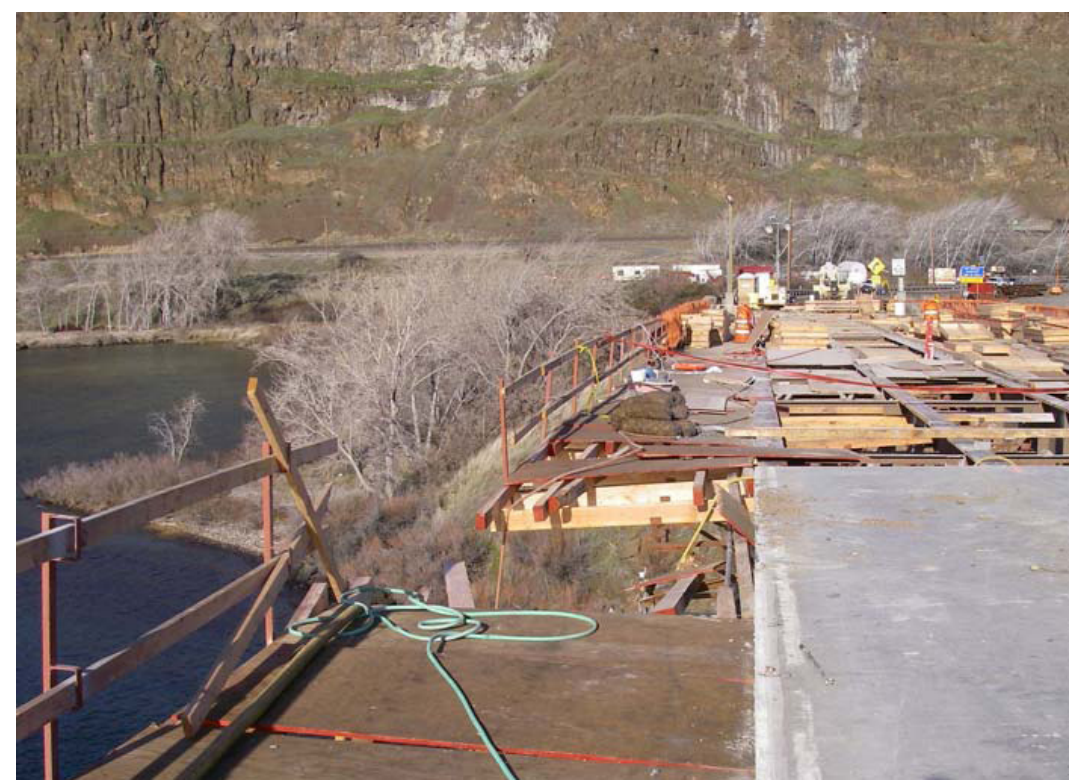

Photo 10: Site where excavator tipped over showing damage to guardrail, temporary walkway, and marks caused by excavator sliding

\section{CONTRIBUTING FACTORS}

- Concrete slab weights were underestimated

- Length of rigging chain used on incident slab was too long.

- Concrete slab hung vertically, increasing height of lift to clear the guardrail.

- Load extended past the tipping radius of the excavator.

- Workers were on foot in the intended swing radius of suspended slab. 


\section{CAUSE OF DEATH}

The medical examiner listed the cause of death as blunt force chest trauma.

\section{RECOMMENDATIONS AND DISCUSSION}

On this complex job site, three parties had distinct responsibilities addressed by the following recommendations; the employer, the operator, and the site supervisor.

\section{Recommendation 1: Employers should plan excavator picks to ensure that the stability of the machine can be maintained by the operator while lifting freely suspended loads.}

\section{Discussion:}

Employers are responsible for and should plan for the following factors that may affect the stability of the excavator:

- Non-specific load charts

- Load weight estimations

- Using the excavator as a crane
- Rigging system used

- Site conditions

The operator did not have load charts specific to the Hitachi UH083LC excavator being used. Instead, the employer used the load charts for another model excavator they believed to be most similar. The employer attempted, but was unable to locate the specific load charts for the excavator.

According to the Code of Federal Regulations 29 CFR 1926.602(b)(3) and Washington Administrative Code WAC 296-155-615(2)(c), it is required that excavators have load charts in the cab:

"The safety requirements, ratios, or limitations applicable to machines or attachment usage covered in Power Crane and Shovel Association's Standards No. 1 and No. 2 of 1968, and No. 3 of 1969, must be complied with, and must apply to cranes, machines, and attachments under this part." ${ }^{2,3]}$

Power Crane and Shovel Association (PCSA) Standard No. 3, section 7.24 states:

"A load rating chart shall be located on the excavator to be available to the operator from his position at the control stand. ${ }^{\text {[4] }}$ 
After the incident, the employer purchased a new excavator equipped with the manufacturer's load chart installed in the cab. The employer instructed the operators to keep lifts within the limits of the load rating chart. According to the safety manager, the new model is lighter and stronger than the Hitachi model UH083LC excavator.

Like cranes, excavators have a diminished lifting capability when the load is over the side; therefore the accurate estimation of load weight is vital to maintain safe lifting practices.

In the pre-planning phase of the project, the weights of the concrete deck slabs to be cut were estimated based on a density of 125 pounds per cubic foot and the dimensions of a few slabs. The dimensions used had a thickness of 8 inches and a fixed corner to corner length. According to the safety manager, these dimensions were not applicable to all slabs. The variations in the thickness of the deck and the subsequent overlays contributed to underestimations of the weights. In addition, using the same corner to corner length may have resulted in different size and shape slabs. For example, a 10 foot corner to corner length for a 10 foot $x 10$ foot slab would be a square of $100 \mathrm{ft}^{2}$. A 5 foot $x 8.7$ foot rectangular slab with the same 10 foot corner to corner length would be only $43.3 \mathrm{ft}^{2}$ in area.

Weight estimates determine if any of the planned lifts are a critical lift. When the lifting load weight is heavier than $75 \%$ of the rated capacity of the lifting equipment, it is recommended that critical lift precautions be taken. Critical lift precautions include: ${ }^{[5]}$

- Supporting surface - the ground must be compact and stable.

- Blocking - unless crane sits on a concrete pad, outrigger blocking must be used and crawlers should be on pads or cribbing.

- Level - machinery deck or boom foot pins must be absolutely level

- Load - load weight must be determined exactly.

- Center of gravity - the location of the load's center of gravity must be determined and the hook positioned above it.

- Load radius - the radius must be measured exactly.

- Boom length - the boom length must be determined exactly.

- Boom angle - the boom angle, if necessary for determining the machine's capacity, must be determined exactly. Do not rely on the machine's boom angle indicator.

- Wind - wind effects must be considered and the lift delayed if the wind loads are significant. If the wind speeds are in excess of $30 \mathrm{mph}$ do not make the lift. If the speeds are more than $20 \mathrm{mph}$ consider postponing it. 
- Load rigging - check for adequacy and security. The weight of rigging must be known exactly.

- Operation - all control, machine and load movements must be made as slowly and smoothly as possible.

The initial lifting plans estimated that the weight of the concrete slabs varied from 4,200 pounds to 4,800 pounds. Table 3 shows the percent of the load capacity based on the EX200LC excavator load charts used in the preplanning phase, and if any lift would be considered a critical lift.

Table 3: Lifting Plan Weight Estimates and Presence of Critical Lift

\begin{tabular}{|l|c|c|c|c|}
\hline Plan Date & $\begin{array}{l}\text { Estimated } \\
\text { Weight (Ibs) }\end{array}$ & $\begin{array}{l}\text { Load Height X } \\
\text { Radius Distance (ft) }\end{array}$ & $\begin{array}{l}\text { Percent of Load } \\
\text { Capacity }^{\mathbf{a}}\end{array}$ & Critical Lift \\
\hline \multirow{3}{*}{$11 / 21 / 2007$} & \multirow{3}{*}{4,200} & $15 \times 20$ & $49.6 \%$ & No \\
\cline { 3 - 5 } & & $15 \times 25$ & $68.1 \%$ & No \\
\cline { 3 - 5 } & & $10 \times 20$ & $50.1 \%$ & No \\
\cline { 3 - 5 } & \multirow{3}{*}{$11 / 21 / 2007$} & $10 \times 25$ & $70.4 \%$ & No \\
\cline { 3 - 5 } & \multirow{3}{*}{4,800} & $15 \times 20$ & $56.7 \%$ & No \\
\cline { 3 - 5 } & & $15 \times 25$ & $77.8 \%$ & Yes \\
\hline \multirow{3}{*}{$12 / 27 / 2007$} & \multirow{3}{*}{4,200} & $10 \times 20$ & $57.2 \%$ & Yes \\
\cline { 3 - 5 } & & $10 \times 25$ & $80.4 \%$ & No \\
\cline { 3 - 5 } & & $15 \times 20$ & $49.6 \%$ & No \\
\cline { 3 - 5 } & & $10 \times 20$ & $68.1 \%$ & No \\
\cline { 3 - 5 } & & $10 \times 25$ & $70.4 \%$ & \\
\cline { 3 - 5 } & & & & \\
\hline
\end{tabular}

a. Percent calculated based of EX200LC excavator load charts that employer used

The initial work plan was for the concrete slabs to stay within a radius of 19.5 feet over the side of the excavator. At a height of either 15 or $10 \mathrm{feet}$, this lift would not be a critical lift at any of the estimated weights. However, a critical lift would occur with the estimated weight of 4,800 pounds if the boom was at a height of either 10 or 15 feet and the load was extended to a radius of 25 feet over side.

Table 4 shows the percent of load capacity based on the EX200LC excavator load charts for the actual concrete slab involved in the incident and whether or not it would be considered a critical lift. 
Table 4: Fatal Lift and Presence of Critical Lift

\begin{tabular}{|l|c|c|c|}
\hline $\begin{array}{l}\text { Actual Slab Weight } \\
\text { (lbs) }\end{array}$ & $\begin{array}{l}\text { Load Height X } \\
\text { Radius Distance (ft) }\end{array}$ & $\begin{array}{l}\text { Percent of Load } \\
\text { Capacity }^{\mathbf{a}}\end{array}$ & Critical Lift \\
\cline { 2 - 4 } 6 & $15 \times 20$ & $78.1 \%$ & Yes \\
\cline { 2 - 4 } & $15 \times 25$ & $107 \%$ & Yes \\
\cline { 2 - 4 } & $10 \times 20$ & $78.7 \%$ & Yes \\
\cline { 2 - 4 } & $10 \times 25$ & $111 \%$ & Yes \\
\hline
\end{tabular}

a. Percent calculated based of EX200LC excavator load charts that employer used

The actual concrete slab involved in the incident weighed 6,600 pounds, and was a critical lift at a radius distance of 20 feet over side with the load at a height of either 15 or 10 feet. This load, at a radius of 25 feet over side, surpassed the capacity of the load charts used in the preplanning phase at either height.

Employers can check the weight of the material they are lifting using a dynamometer. Dynamometers are crane scales that are designed to be used on the load line for checking weights suspended from the hook. ${ }^{[6]}$

While using the excavator as a crane, the operator encountered various hazards; such as, controlling the position of the slab, having workers nearby while performing picks, and the effect of the wind on the slab. ${ }^{[7]}$

As the operator was lifting the concrete slab and swinging it to the left, he attempted to adjust for the slab hanging more vertically than was planned by arming out the load. He inadvertently extended the slab past the excavator's designated safety radius and it became unstable. To regain stability, the operator armed in the slab after it had already passed below the edge of the bridge deck due to excavator tipping. Instead of stabilizing the excavator, arming-in caused the excavator to slide sideways. According to the DOSH inspector, the operator used a common corrective measure for excavators by arming in the load. On the ground or a solid supporting surface, arming in the load would allow the operator to lower the load, thus reducing the force applied to the excavator. A solid surface on which to lower the load and relieve the force exerted on the excavator may have prevented it from tipping over the bridge.

Load chart ratings apply only when the load is picked up directly under the boom tip. Load shifting on either side of the boom tip causes side loading. Side loading can also occur when: ${ }^{[5]}$

- The load is swung rapidly.

- The swing brake is applied suddenly.
- The load is dragged or pulled sideways.

- The lifting machine is not level.

- During tilt-up operations 
It was reported by one witness that the operator started to swing the load to the left until he noticed a carpenter in that area. He then swung the load to the other side faster than normal. The rapid load swing may have caused side loading, which would have decreased the capacity of the excavator.

Faster movement combined with the $26 \mathrm{mph}$ wind could have further decreased the load capacity of the excavator. The employer should have considered postponing the lift because the wind speed exceeded $20 \mathrm{mph}^{[5]}$

Prior to starting the project the employer decided to use a 2 leg bridle sling rigging system when needing to work around the transverse diaphragms. According to the safety manager, this system was probably chosen because it was the simplest and fastest system to use.

The employer could have used a three or four legged bridle system to remove the deck panels with transverse diaphragms. The addition of a third or fourth leg to the bridle system could have provided better load control, preventing the need to raise the load over the guardrail; but it would not provide greater load capacity. When a bridle system has three or four legs, you cannot assume that the weight of the object being lifted is shared evenly across the legs. ${ }^{[8]}$

In situations where an excavator is being used as a crane and the suspended load cannot be lowered to solid ground, employers should consider using rigging systems that provide more load control, such as a three or four legged bridle system.

Employers should coordinate with site supervisors and review the work to be completed each day to ensure that workers will not be in the swing radius of the picks. Site supervisors should also monitor wind and weather conditions and communicate to operators who may be at risk. Employers should also contact manufacturers to determine what weather conditions would be considered hazardous for machine use.

\section{Recommendation 2: Employers should ensure that operators participate in project and task pre-planning and Job Hazard Analysis (JHA) activities.}

\section{Discussion:}

Prior to starting the project, the employer conducted a JHA and performed a load test with a Jersey barrier. A JHA is a procedure used to review each job, identify potential 
hazards, and design actions and procedures to eliminate or control the hazards. To conduct a JHA, determine:

- What are the job tasks.

- What are the hazards.

- How hazards could arise.

- If the tools and machine are right for the job and if they are in good condition.

- What are the other potential contributing factors to the hazard.

- How likely it is that the hazard could occur.

- What could go wrong. ${ }^{[9]}$

The results of the JHA and the load test were verbally communicated to the operator. However, no written JHA was performed along with operators for the operation of the excavator on this job and work site.

When operators are involved in the pre-planning and JHA activities, they can provide input about hazards they foresee and how to mitigate them. The American National Standard Institute's (ANSI) Standard A10.1 - 2011, Pre-Project Planning \& Pre-Task Safety and Health Planning, section 8.1.4, Contractors - Pre-Task Safety and Health Planning, states:

"That all affected craft labor shall be informed about the task hazard analysis and required to participate in the process. Participation shall include discussion on accomplishing the task step by step with appropriate work activities, communication and personal protective equipment. ${ }^{\text {:10] }}$

Operators should also participate in load testing using the machine under similar work conditions. While completing the load test, operators should practice responding to possible upset conditions, such as sudden load shifts or the machine becoming unstable.

\section{Recommendation 3: Employers should consider installing an audible and/or visual load safety warning device or a safe load indicator to alert operators before the object handling capacity or load moment is reached.}

\section{Discussion:}

Load moment refers to the product of a load mass and a moment arm length. It is used as a guideline to determine crane capacity. In this case, the excavator was being used like a crane for lifting purposes. Where the concreted slab was the load mass and the 
moment arm was the horizontal distance from the load center of gravity and the center rotation of the excavator (approximately 25 feet). ${ }^{[11]}$

When the operator of the excavator armed out the concrete slab extending it to approximately 25 feet he increased the force being applied to the excavator by $20 \%$ and surpassed the safe lifting capacity of the excavator.

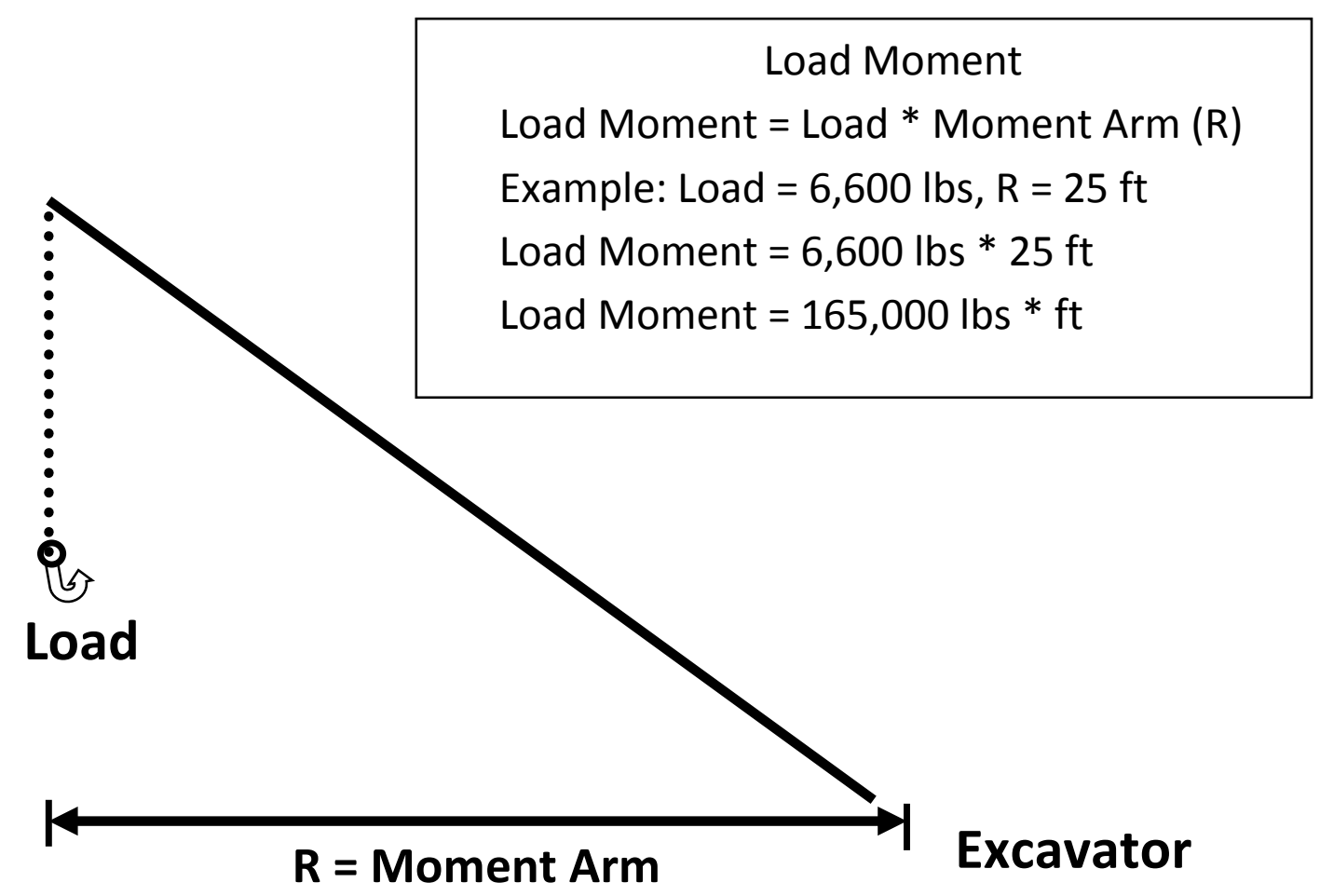

Diagram 2: Excavator boom with suspended load characterizing load moment

Safe load indicator systems with acoustic and visual warning devices are intended to inform machine operators when the lift is approaching an overload condition. Load moment limiters will physically lock the machinery if conditions become unsafe. ${ }^{[12]}$ Some newer models of excavators and other earthmoving machines are equipped with these devices, but they may also be retrofitted to older machines.

Load safety warning systems are considered operator aides. The intent is to provide the operator with as much relevant information as possible to perform their duties as safely as possible. The presence of load safety warning systems does not diminish the need for operators to be properly trained and to have equipment properly maintained.

Some countries have regulations that require lifting equipment to be equipped with these kinds of technologies. The United Kingdom's Health and Safety Executive (HSE) 
Lifting Operations and Lifting Equipment Regulations (LOLER) approved code of practice and guidance states that:

"If the rated lifting capacity for an excavator or the backhoe portion of a backhoeloader is greater than 1 tonne (or the overturning moment is greater than $40000 \mathrm{Nm}$ ) then the machine must be fitted with:

a) a boom lowering control device on the raising (main) boom cylinder(s) and which meets the requirements of ISO 8643:1997 and

b) an acoustic or visual warning device which indicates to the operator when the object handling capacity or corresponding load moment is reached. ${ }^{\text {[13] }}$

Because the operator did not have accurate weight estimates for the concrete slabs or load charts specific to the excavator, it is possible that he believed the weight of the concrete slab was within a safe range even when extended past the guardrail. A monitoring instrument that alerts the operator when the load is close to exceeding the safe operating range might have allowed the operator to respond before the load became unstable.

Operators should know how much a load weighs and use the appropriate load chart. They should never use signs of tipping as a warning of overload.

Other guidance equipment for machinery includes safe slew indicators, and global positioning systems (GPS). Slew indicators provide warnings to operators if the machinery is in danger of sliding uncontrollably. GPS systems can be used to provide the operator with a visual representation of the area they are working on without having to leave the cab. ${ }^{[5,8]}$

Safe load indicators, load safety warning systems, and guidance equipment can be purchased and retrofitted for excavators and other lifting machines. Employers should consult with manufacturers about best practices for retrofitting machinery.

\section{Recommendation 4: Operators should perform a JHA following any changes in the intended work plan prior to changing the operational work plan.}

\section{Discussion:}

When the operator saw stress on the chain during the previous lift, he asked the rigger for more length in the chain. This differed from the intended operational plan and changed the dynamics of the lift. Extending the length of the rigging chain caused the 
concrete slab to hang more vertically than horizontally. This required the operator to raise the load to clear the guardrail. When the operator chose to arm out, instead of booming up the load to clear the guardrail, he exceeded the tipping point for the load.

OSHA recommends that a JHA be conducted on jobs that have undergone changes in processes and procedures ${ }^{[9]}$ If the operator had conducted a JHA prior to lengthening the rigging chain, he might have realized that the concrete slab would have hung more vertically and affected his ability to potentially keep the load in the designated safety zone (inside the guardrails).

An example JHA form is included in Appendix A.

Both The Washington State Department of Labor and Industries (L\&I) and OSHA have resources for JHAs.

- L\&l's Job Hazard Analysis PowerPoint slides which provide training on JHAs can be found at http://wisha-training.Ini.wa.gov/training/JHA/JHA2009.ppt.

- Examples of blank and completed JHA forms can be found on the L\&I website at http://www.Ini.wa.gov/Safety/Topics/AToZ/JHA/PDFs/SampleJHA.doc

- OSHA has created a booklet with information about JHAs that can be found at https://www.osha.gov/Publications/osha3071.html

\section{Recommendation5: Operators should communicate with riggers to address any lift that does not follow the intended lifting plan.}

\section{Discussion:}

Initial lifting plans are created to ensure the safety of all workers involved in the process. After the operator asked the rigger to extend the chain, the second concrete slab hung more vertically than the first slab. This was not the intended position for moving the suspended slab. The operator or rigger should have communicated that the slab was out of intended horizontal position and stopped the lift. They could have then readjusted the rigging to ensure that the position of the concrete slab no longer created a hazard and followed the intended lifting plan. 


\section{ACKNOWLEDGEMENTS:}

This report was reviewed by stakeholders from labor and business communities and various Washington State and Federal worker safety agencies. Though we are unable to acknowledge specific individuals for their contributions to this report, we would like to recognize the following for their help and support of the FACE mission and objectives:

- $\quad$ The Employer's representative involved in the incident

- $\quad$ Division of Occupation Safety and Health (DOSH)

- $\quad$ Federal FACE Program Management (NIOSH)

- $\quad$ Safety \& Health Assessment \& Research for Prevention (SHARP)

- Washington State Attorney General's Office 


\section{APPENDIX A: JOB HAZARD ANALYSIS EXAMPLE FORM}

Date of analysis: Participants

\section{Job Hazard Analysis}

\begin{tabular}{|c|c|c|}
\hline How people get hurt & What causes them to get hurt? & What safe practices or PPE are needed? \\
\hline Ladders tipping over & $\begin{array}{l}\text { - Ladder was not on a level surface } \\
\text { - Ladder was on soft ground and the } \\
\text { leg sunk in } \\
\text { - The person reached out too far } \\
\text { - The ladder wasn't high enough to } \\
\text { reach up safely - the person stood } \\
\text { up near the top of it } \\
\text { - Ladder broken or damaged }\end{array}$ & $\begin{array}{l}\text { - Set ladder feet on solid level } \\
\text { surfaces. } \\
\text { - When reaching out, keep belt buckle } \\
\text { between the side rails of the ladder. } \\
\text { - Do not stand on the top of a } \\
\text { stepladder or on the first step down } \\
\text { from the top. } \\
\text { - Replace or repair ladder }\end{array}$ \\
\hline Lifting heavy objects & $\begin{array}{l}\text { - Trying to lift too heavy objects } \\
\text { - Bending over at the waist when } \\
\text { lifting } \\
\text { - Turning (twisting) back while lifting }\end{array}$ & $\begin{array}{l}\text { Use proper lifting practices (bend } \\
\text { knees, don't twist) } \\
\text { - For very heavy objects, use } \\
\text { mechanical devices or get another } \\
\text { person to help. }\end{array}$ \\
\hline Slipping on the floor & $\begin{array}{l}\text { - Spilled liquids not cleaned up } \\
\text { - Small objects are dropped on the } \\
\text { floor and left there } \\
\text { - People wear the wrong type of shoes } \\
\text { for conditions }\end{array}$ & $\begin{array}{l}\text { Wipe up all spills, and pick up } \\
\text { dropped items, immediately. } \\
\text { Wear sturdy shoes with slip-resistant } \\
\text { soles; }\end{array}$ \\
\hline Using the bench grinder & $\begin{array}{l}\text { - Flying particles get in eyes } \\
\text { - If grinder wheel breaks, large chunks } \\
\text { fly off at high speed } \\
\text { - High noise level can injure hearing }\end{array}$ & $\begin{array}{l}\text { Wear safety glasses and earplugs } \\
\text { when using grinder. } \\
\text { Keep tongue guards adjusted } \\
\text { properly (see sticker on grinder for } \\
\text { spacing). }\end{array}$ \\
\hline
\end{tabular}




\section{REFERENCES}

1. Fraantoine. Bridge Engineering Chapter 11 Diaphragms and Cross Frames. 2010 [cited 2012 May 16, 2012]; Available from: http://www.scribd.com/doc/38249737/Bridge-DesignDiaphragms-Ch11notes-pdf.

2. Occupational Safety and Health Administration. Safety and Health Regulations for Construction. Material Handling Equipment 1970 [cited 1926.602; Available from: http://www.osha.gov/pls/oshaweb/owadisp.show document?p table=STANDARDS\&p id=1422 $\underline{4}$.

3. Material handling equipment, in 2(c), Washington State Department Labor and Industries. 2007.

4. Power Crane and Shovel Association. Mobile Hydraulic Excavator Standards, in PCSA Standard No. 3. 1969, Construction Indsutry Manufacturers Association.

5. Dickie, D.E., Mobile Crane Manual. 1982, Toronto: Construction Safety Association of Ontario.

6. Construction Plant-hire Association. Excavators used as Cranes. 2000, Construction Plant-hire Association: London. p. 2.

7. The Office of Health Safety and Security. Hoisting and Rigging Fundamentals. 2002, U.S. Department of Energy. p. 52-53.

8. United States Department of Labor. Job Hazard Analysis, Occupational Safety and Health Administration, Editor. 2002, U.S. Department of Labor.

9. American National Standard Institute. Pre-Project and Pre-Task Safety and Health Planning, in Contractors - Pre-Task Safety adn Health Plannning. 2011, American Society of Safety Engineers: Des Plaines, Illinois. p. 2.

10. SkyAzul Equipment Solutions., What is Load Moment? , SkyAzul: Middletown. p. 1.

11. Occupational Safety and Health Administration. Safety and Health Regulations for Construction Definitions, in 1926.1401, Occupational Safety and Health Administration, Editor. 2010.

12. Construction Plant-hire Association, Construction Confederation., The Construction Equipment Assoication, Health and Safety Executive. Guidance on Lifting Operations in Construction When Using Excavators. 2009, Construction Plant-hire Association: London. p. 1-7. 


\section{INVESTIGATOR INFORMATION}

Todd Schoonover has a PhD in Industrial Hygiene from the University of Illinois at Chicago. He is a Certified Industrial Hygienist $(\mathrm{ClH})$ and Certified Safety Professional (CSP). Todd is currently the Principal Investigator for the WA FACE program.

Eric Jalonen has a Master's in Public Health (MPH) from East Carolina University. He is a Research Investigator with the WA FACE program.

Randy Clark has a BA from The Evergreen State College. He is a Research Analyst with the WA FACE program.

\section{Washington State FACE Program Information}

The Washington State Fatality Assessment and Control (WA FACE) program is one of many workplace health and safety programs administered by the Washington State Department of Labor \& Industries' Safety \& Health \& Research for Prevention (SHARP) program. Under a cooperative agreement with the National Institute for Occupational Safety and Health (NIOSH), WA FACE collects information on occupational fatalities in WA State and targets specific types of fatalities for evaluation. WA FACE investigators evaluate information from multiple sources. Findings are summarized in narrative reports that include recommendations for preventing similar events in the future. These recommendations are distributed to employers, workers, and other organizations interested in promoting workplace safety. NIOSH-funded, state-based FACE programs include: California, lowa, Kentucky, Massachusetts, Michigan, New Jersey, New York, Oregon, and Washington. WA FACE does not determine fault or legal liability associated with a fatal incident. Names of employers, victims and/or witnesses are not included in written investigative reports or other databases to protect the confidentiality of those who voluntarily participate in the program.

Additional information regarding the WA FACE program can be obtained from:

Washington State FACE Program

www.Ini.wa.gov/Safety/Research/FACE/default.asp

PO Box 44330

Olympia, WA 98504-4330

1-888-667-4277 